\title{
Laicidad: principio ético de inclusión de las perspectivas religiosas en los dilemas morales.
}

\section{Secularism: ethical principle of inclusion of religious perspectives in moral dilemmas.}

Esta obra está bajo una Licencia Creative Commons Atribución 4.0 Internacional. DOI: $10.32870 /$ sincronia.axxiii.n75.1a19

\section{José Salvador Arellano Rodríguez ${ }^{1}$}

Facultad de Filosofía

Universidad Autónoma de Querétaro

jose_arellano28@yahoo.com.mx

(MÉXICO)

\section{Eduardo Farías Trujillo ${ }^{2}$}

Facultad de Filosofía

Universidad Autónoma de Querétaro

arktos11@gmail.com

(MÉXICO)

Recibido: 01/07/2018

Revisado: $22 / 10 / 2018$

Aprobado: 25/11/2018

\section{RESUMEN}

En este artículo se aborda la diferencia entre laicidad y distintas perspectivas religiosas al tratar temas en el campo de la Bioética. Nuestro objetivo es mostrar cómo una reflexión laica, en los dilemas bioéticos, garantiza la libertad de conciencia de todos los individuos, pues promueve el

\footnotetext{
${ }^{1}$ Doctor en Filosofía por la Universidad de Guanajuato. Profesor de Tiempo completo, Facultad de Filosofía de la Universidad Autónoma de Querétaro. Miembro del Sistema Nacional de Investigadores, nivel I. Contacto: Av. 16 de septiembre 57 altos. Patio Barroco, Centro Histórico CP. 76000. Correo electrónico: jose_arellano28@yahoo.com.mx.

2 Maestro (M.A.) en Teología y Ciencias Patrísticas por el Instituto Patrístico Agustiniano de la Pontificia Universidad Lateranense de Roma. Miembro de la Unidad de Bioética, Facultad de Filosofía de la Universidad Autónoma de Querétaro. Contacto: Av. 16 de septiembre 57 altos. Patio Barroco, Centro Histórico CP. 76000. Correo electrónico: arktos11@gmail.com.
} 
pluralismo y la diversidad, tanto cultural como religiosa. La laicidad, desde nuestra perspectiva, no significa un ataque a la religión ni mucho menos un anticlericalismo, sino, antes bien, una condición de diálogo que posibilita la inclusión de creencias y posturas religiosas en un marco de tolerancia y pluralidad.

Palabras clave: Bioética. Religión. Teología. Laicidad.

\begin{abstract}
This article deals with the relationship between secularism and different religious perspectives, with the aim of discovering that secularism, in bioethical dilemmas, guarantees the freedom of conscience of all individuals, as it promotes pluralism and diversity, both cultural as well as religious. Secularism does not mean attacking religion or anticlericalism, but a condition of possibility to favor a coexistence that allows deliberative dialogue in bioethics with two indispensable contributions: tolerance and anti-dogmatism. It becomes clear that the ideologization of science and religion is what gives rise to the impossibility of dialogue. From the ultimate status of science, bioethics, based on secularism, opens horizons to different religious beliefs, because it recognizes the autonomy of moral agents as a source of responsibility and guarantee of community dialogue. In this way, secularism is a minimum that enables the maximum of the ideal of happiness, which can be developed in the community of each religious perspective.
\end{abstract}

Keywords: Bioethics. Religion. Secularism. Theology.

\title{
Introducción
}

La función de la laicidad en la bioética es proponer un ámbito en el que los acuerdos de convivencia humana, es decir, las leyes éticas, no sean aceptados porque hayan tenido como origen un mandato divino o sagrado, sino porque son una construcción histórica, social y plural de los seres humanos, considerados y aceptados como autónomos y responsables. Las obligaciones morales de las perspectivas religiosas son tales en tanto las personas deciden formar parte de alguna comunidad particular. 
Tal como lo expresa Hottoi (1995: 1-10), la así llamada bioética es una excelente indicación de las condiciones en las que surge la cuestión ética en las modernas sociedades complejas desarrolladas. Por tal motivo, definir una ética adaptada a las características específicas de estas sociedades implica distinguir dos formas de obligaciones éticas: la de las reglas dogmáticas derivadas de la pertenencia a comunidades particulares, lo que se puede denominar el ámbito de la deliberación moral, y la de una moral formal en la que está indicado el ideal de una comunidad secular cuya inevitable ambigüedad debe ser a la vez peculiar y universal.

Desde esta perspectiva, una secularidad correcta (sic) y una laicidad sana (sic) -que no sean ni secularismo ni laicismo- son condiciones necesarias de posibilidad para el respeto a la dignidad de los humanos, a la paz social y a la legitimidad política. Es evidente, desde esta perspectiva, que la laicidad se convierte en un proceso de construcción de cada ser humano, pues la configuración de su propia personalidad no estriba únicamente en la exégesis de la heteronomía que le llega de lo alto, sino en la autonomía ${ }^{3}$ que le permite, con base en la reflexión y la interiorización, establecer para sí mismo, y para los demás, una ley, valores y criterios de convivencia humana que hagan posible el conocimiento y el cuidado de sí mismo, de los otros seres humanos, de los demás seres vivos no humanos y de la casa común de todos, el planeta Tierra.

Desde luego que, cuando se habla de laicidad, se parte de la constatación de que no existe un único pensamiento laico, así como no existe una religión única. Es necesario, por tanto, partir de perspectivas de laicidad y de perspectivas religiosas. Así como se pueden identificar características comunes a las diferentes posturas religiosas, es posible identificar un conjunto de características comunes a todas las concepciones laicas. En este artículo, se usa el

\footnotetext{
${ }^{3}$ Los límites a la autonomía están dados por la propia capacidad del sujeto que la ejerce, así como por los derechos de otros. La libertad debe ir acompañada de responsabilidad en su sentido global, esto es, ejercerla hacia el pasado, el presente y el futuro, así como asumir las consecuencias. El diálogo y el consenso no significan el abandono de convicciones propias.
} 
término "laicidad" para hacer referencia, de manera neutral, a este conjunto de características identificadas como concepciones no religiosas y no confesionales. Pero, aun cuando Bovero (2013) afirma "se trata de asunciones mínimas, per se insuficientes para articular una visión del mundo unívoca y, sin embargo, selectivas de una cierta clase (en sentido lógico) de concepciones" (Bovero, 2013, p. 263), la laicidad posibilita el diálogo deliberativo en la bioética con dos aportaciones indispensables: la tolerancia y el antidogmatismo. ${ }^{4}$

\section{La laicidad en la bioética}

La laicidad permite poner al descubierto, entre otros, tres enemigos u obstáculos para la plena realización de la bioética: el determinismo biológico -que es la ciencia devenida en ideología-, la metafísica y las perspectivas religiosas convertidas en ideología. En el diálogo bioético es indispensable excluir estos tres fundamentalismos evitando posiciones extremas, y proponer, más bien, criterios comunes que permitan, mínimamente, la convivencia pacífica entre los seres humanos, i. e., ser bueno y vivir bien, el cuidado de uno mismo, el respeto por los seres vivos, la tolerancia, el reconocimiento de que nadie puede adjudicarse el derecho de monopolizar la verdad, el asumir los motivos de los demás como propios (Blackburn, 2002, p. 150). Desde luego que esto requiere poner la mirada en la humanidad, lo que significa tener una actitud de benevolencia, una ética cordial, una ética de mínimos, ética de la solidaridad (Rosas, 2011, p. 10-25) que haría plausible establecer ciertos valores compartibles en una sociedad plural, aceptando la posibilidad de cuestionar las propias convicciones desde otras posiciones, y

\footnotetext{
${ }^{4}$ Uno de los mayores peligros del fundamentalismo es su argumento de que la vida depende de Dios y, por tanto, no se puede interferir en su génesis, en su desarrollo, en su desenlace. Lo cual no es verdadero, porque, si se aceptara la idea de que el ser humano para sí mismo es providencia de Dios, como dijo Santo Tomás de Aquino, no hay que pasar por alto que Dios no es un Ente o un Agente Supremo que imponga leyes y actúe por sí mismo desde fuera. Suponiendo, sin conceder, que Dios fuera el Corazón y el Fondo de todo cuanto es, no obstante, no tendría más ojos ni manos que la realidad entera y los seres humanos en ella, pues, como dice el Nuevo Testamento, "en Él nos movemos, vivimos y somos" y Él en nosotros, en todo cuanto es. Esto significa, entonces, que la creación continúa, y tiene lugar a través de las propias criaturas, a través de la propia materia, respecto de la cual no se ha comprobado científicamente qué es ni si es eterna. Cuando en temas de bioética algunas denominaciones religiosas dicen que los científicos juegan a ser dioses, se tiene que responder que no se trata de "jugar a ser dioses", sino de encarnar el juego divino de la creación.
} 
apreciar el enriquecimiento que aporta la competencia profesional interdisciplinaria y la autenticidad en los acuerdos (Rodríguez, 2010, pp. 7-8). No se trata de proclamar que hay una oposición irreconciliable entre las perspectivas religiosas y las ciencias, sino en delatar que esa oposición se da entre las religiones y las ciencias ideologizadas (Carta apostólica, n. 50). ${ }^{5}$

La bioética es, ante todo, una inter y (Lolas, 2012 p. 12) que se ha venido gestando y desarrollando, por lo menos, desde la primera mitad del siglo XX. Su objetivo es reflexionar acerca de dilemas morales contemporáneos. Esta nueva área de reflexión moral forma parte de lo que desde el ámbito filosófico se ha denominado giro aplicado. El giro moral aplicado surge desde la imperiosa necesidad, ya no sólo de reflexionar sino de encontrar soluciones inmediatas a nuevos problemas que se originan a partir de la investigación científica y tecnológica con seres humanos y con seres no humanos, como el fenómeno creciente de la globalización (Gracia, 2002, pp. 27-39) y del deterioro medioambiental, así como dilemas inéditos que plantean casos y eventos específicos, producto principalmente del desarrollo científico y tecnológico.

Por ello, los problemas y las confusiones morales son cada vez más complejos, especialmente por el contacto frecuente entre las sociedades, pues se vive en una aldea global, lo que provoca que entren en contacto, y conflicto, los diferentes sistemas de moral presentes en cada una de esas comunidades particulares. La clonación de seres humanos; la experimentación con embriones; los trasplantes de órganos; el aborto; la investigación con animales humanos y no humanos; la neurología y la nanotecnología; los organismos genéticamente modificados; la muerte digna son algunos de los fenómenos que día a día exigen nuevas formas de reflexión y análisis; nuevas referencias para los juicios morales, dado que no

\footnotetext{
${ }^{5}$ Hace ya algunos años, el papa Pablo VI proponía y pedía que "En las situaciones concretas, y habida cuenta de las solidaridades que cada uno vive, es necesario reconocer una legítima variedad de opciones posibles. Una misma fe cristiana puede conducir a compromisos diferentes" (Gaudium et spes 43: AAS 58 [1966] 1061). La Iglesia invita a toda la comunidad cristiana a la doble tarea de animar y renovar el mundo con el espíritu cristiano, a fin de perfeccionar las estructuras y acomodarlas mejor a las verdaderas necesidades actuales. A mujeres y hombres cristianos que a primera vista parecen oponerse partiendo de opciones diversas, pide la Iglesia un esfuerzo de recíproca comprensión benévola de las posiciones y de los motivos de los demás; un examen leal de su comportamiento y de su rectitud sugerirá a cada cual una actitud de caridad más profunda que, aun reconociendo las diferencias, les permitirá confiar en las posibilidades de convergencia y de unidad. «Lo que une, en efecto, a los fieles es más fuerte que lo que los separa.
} 
tenemos, actualmente, una norma fundamental o un principio que pudiera determinar el modo como se debería deliberar y actuar.

Todos los hombres deben aprender hoy a vivir en dos niveles: por un lado, sus convicciones morales, sus identidades, pertenencias personales y privadas de la comunidad; y, por otro lado, de la moral formal y universal, que nos invita a relativizar el primer nivel y que consiste en respetar la autonomía de los demás. Es el segundo nivel lo que impide que el primero se vuelva fanático y dogmático, pero la dualidad de los laicos implica algo específico y difícil: a saber, que su responsabilidad particular y concreta es la promoción real de la universalidad, la tolerancia y la libertad. La moral secular del primer nivel tiene como contenido la promoción de la moral universal del segundo nivel. Por esta razón, la comunidad secular es a la vez peculiar y universal; tiene y no tiene una identidad propia que la distinga del resto de la humanidad. También existe su ambigüedad, a menudo denunciada, pero inevitable (Hottois, 1995, p. 9).

\section{El estatus último de la ciencia}

Se ha dicho que la bioética es un área inter y multidisciplinaria. Los dilemas morales, aquellos que suscitan la ciencia y la tecnología, son problemas, en ocasiones, sumamente complejos, por lo que requiere del conocimiento de expertos en ramas distintas del saber. Es necesario contar con conocimientos en derecho, salud pública, biología, neurociencias, ética, psicología y medicina, por mencionar algunos.

Las tradiciones religiosas pueden y deben estar presentes en y contribuir a las deliberaciones y decisiones éticas autónomas, si cuando proponen, sin imposiciones, criterios de valores, articulan su perspectiva con los datos de la tecnociencia ${ }^{6}$. Por ejemplo, en los

\footnotetext{
${ }^{6}$ Como dice González Valenzuela (2008), la bioética debe ser laica y plural. Porque la bioética se desarrolla con base en conocimientos científicos surgidos de las ciencias biológicas y de las ciencias filosóficas y sociales y porque se circunscribe al ámbito secular del saber fundado en los hechos y en razones, por esto, le es inherente la laicidad. Pero
} 
debates sobre trasplantes, esa articulación pronto funcionó bastante bien. En los debates sobre adecuación del esfuerzo terapéutico, la integración funcionó sólo a medias. En los debates sobre el comienzo de la vida, la integración está todavía estancada, porque no se ha querido asumir el paradigma evolutivo y epigenético en el modo de entender la embriología; y por la resistencia a separar, en la teología moral, los aspectos procreativos y unitivos de la relación sexual (Masiá, 2012, pp. 51-52).

Otro ejemplo que puede ayudar a entender esta premisa es el de la ética de los animales no humanos. Para determinar nuestras responsabilidades con respecto a ellos es necesario que se discutan los principios filosóficos subyacentes al estatus y al valor moral de los animales no humanos (Cortina, 2009, p. 61). No obstante, al mismo tiempo, es necesario contar también con conocimientos que nos ayuden a comprender las características propias de las diferentes especies y los efectos que las acciones humanas tienen sobre ellas y, así, poder prescribir las acciones necesarias para preservarlas. En esta misma vertiente, el derecho se encargaría de diseñar leyes que protejan a los animales no humanos de acuerdo con lo discutido. De esta manera, se hace indispensable un diálogo estrecho entre las distintas disciplinas y una retroalimentación constante. Los expertos en las diferentes áreas deben de estar al tanto de los conocimientos desarrollados en las otras áreas para poder tomar decisiones informadas. Pero si bien es interdisciplinario, el eje de reflexión de la bioética es la filosofía (Hall, 2012, pp. 203-213). Los derechos humanos son el gran invento de la civilización humana, aunque solamente son una invención para los humanos. Los otros seres vivos también necesitan un invento, una creación de esa magnitud, de tal manera que al menos se tenga en cuenta su capacidad de padecer dolor o placer, lo que se ponga en consideración. Una visión de confesionalidad religiosa, que tiene detrás una institución religiosa con sus propios intereses

hay además otra razón básica por la cual la bioética es laica: la bioética es laica, porque presupone la idea de un pluralismo de valores de grupos o individuos, sean o no sean creyentes. No parte de dogmas de fe metafísicos, teológicos o religiosos, sino por la esencial pluralidad y el carácter controvertible que tienen las cuestiones bioéticas, por ello mismo, la bioética filosófica es necesariamente laica. 
políticos, que proclame que el ser humano es el único que tiene valor en sí mismo, podría dar pie a considerar a los animales no humanos bajo el yugo de los derechos humanos. Desde una perspectiva no fundacionista, es decir, desde una perspectiva social-constructivista, no se tienen como punto de partida las categorías trascendentales de dignidad, persona, autoconciencia y derechos humanos absolutos. Tampoco hay necesidad de limitar el concepto de derechos a los derechos humanos -o quizá sería mejor decir que no debemos limitar el uso de la palabra "derecho" de tal manera-. Por supuesto que los seres humanos tienen derechos que no pertenecen a los animales en la gradación de relevancia moral.

Cada ser tiene derechos apropiados a su naturaleza y a sus capacidades. La postura constructivista implica, solamente, que no es necesario un concepto transcendental de los seres humanos, ni una separación de calidad de la dignidad de los humanos y el valor de los animales (Hall, 2012, p. 203).

Lo anterior, porque sólo con esos "otros", los animales no humanos y demás seres vivos no humanos, el homo sapiens sapiens podrá sobrevivir como especie. Los distintos problemas analizados por la bioética tienen que ver con la vida en general, extendiendo de esta manera su campo a cuestiones relacionadas con el medio ambiente, el trato debido a los demás seres humanos y a los otros seres no humanos. En este sentido, por ejemplo, en relación con el tema del aborto, el concepto de persona es totalmente relevante, dado que se hace necesario determinar el momento en el que se puede hablar de la aplicación del estatus de persona. Se habla de persona desde los contextos filosófico, sociológico, fisiológico, psicológico, jurídico, entre otros. De esta manera, si la condición de persona se considera que se debe aplicar al ser humano desde la concepción, sería visto como un asesinato el terminar con su vida en cualquier momento; pero si la definición está acotada a seres humanos con ciertas capacidades cognitivas, entonces es tarea de los neurocientíficos determinar hasta qué etapa del embarazo es permisible su interrupción. De la misma manera, la definición de persona es relevante para el 
tema de la muerte cerebral, pues establece en qué momento un ser humano deja de ser considerado persona y, por tanto, es moralmente admisible retirar un soporte vital.

La respuesta que se dé a cualquiera de las denominadas preguntas fundamentales tiene repercusiones en distintos ámbitos de la bioética, por lo que se convierte en indispensable el contar con un conocimiento claro de los factores que constituyen cada caso para poder deliberar sobre él. Por esta razón, no es éticamente aceptable llegar a emitir juicios éticos sin antes tener una descripción de los elementos nodales del problema tratado. Es necesario establecer definiciones adecuadas, claras y distintas, de los conceptos clave y contar con el suficiente conocimiento de los hechos y de los fenómenos relevantes para poder deliberar, argumentar, emitir un juicio moral razonable y llegar a la toma de decisiones.

La moralidad es un hecho histórico, cuya función es establecer y mantener la solidaridad social, y cuyo desarrollo es producido por las acciones y el diálogo de los miembros de una comunidad. La ética, entendida como una propuesta de carácter inductivo tiene como punto de partida casos específicos, desde los cuales realiza una reflexión crítica que hace posible comprender los fenómenos morales, junto con la autonomía y los derechos humanos, que son la gran creación del homo sapiens.

Esta grandiosa construcción puede salvar a la raza humana y al planeta Tierra con los demás seres vivos que lo habitan, siempre y cuando se acepte que hay conceptos que contienen en sí mismos una imposibilidad, la de establecerles clara y distintamente un espacio lógico, tal como sucede con el concepto de la vida y de la muerte, del ser humano, de la dignidad, etc.

Dado lo anterior, esos conceptos presentan dos dificultades extra, a) la de aplicarles esquemas binarios tales como dentro y fuera, o interno y externo y b) practicar las operaciones de inclusión y exclusión de tipos o casos en esos conceptos. Esa ausencia de límites claros y distintos, definitivos y obligatorios sólo pueden establecerse de manera consensuada. No han sido, no son y no serán fruto de ninguna metafísica, por lo que ningún poder, ninguna potestad puede arrogarse la facultad de establecer esos límites. El ser humano, en consenso con otros 
seres humanos, establece convencionalmente esos límites, i.e., los construye históricamente y los utiliza como un invento, como una creación de la civilización. Una ética como constructo social, histórico y plural se sitúa en la contingencia, porque es existencial, sujeta a los cambios y aportaciones que se producen en los avatares históricos (Arellano, 2013, pp. 170-179). La bioética es una ética civil que se sustenta en la racionalidad humana secularizada, capaz de ser compartida por todos, en un terreno filosófico neutro, más allá de un ordenamiento jurídico y deontológico, y más acá de las convicciones religiosas.

\section{La laicidad permite abrir horizontes a las creencias religiosas}

Se trata de una perspectiva que posibilita hacer frente a esa peligrosa paradoja que persiste en la actualidad, según la cual, por un lado, se tiende a reducir la religión a la esfera privada, sin otorgarle el estatuto de una dimensión constitutiva del ser humano ni de la sociedad y, por el otro, se confunden el ámbito religioso y la esfera política sin que se llegue a establecer una distinción pertinente y necesaria. Las éticas aplicadas, de las que forma parte la bioética, buscan dar respuesta a diversos problemas que afectan a la humanidad. Las sociedades pluralistas precisan dar respuesta a las cuestiones que se les plantean y no pueden hacerlo desde un código único, sino desde esas éticas aplicadas que funcionan como una parte de la realidad social. Las diferentes perspectivas y áreas desde las que se analizan tales dilemas son, por ejemplo, la ciencia, las áreas sociales, la teología, sin descartar las creencias e intereses de quienes se ven inmersos en una problemática de deliberación moral, ni las emociones, los argumentos retóricos e históricos, la simpatía e intuición, la empatía ni los sentimientos. Se constata que el diálogo desde la pluralidad es un requisito dentro del análisis moral hoy en día. Es evidente que las sociedades actuales están compuestas multiculturalmente, gracias, también, al fenómeno de la globalización. La presencia simultánea de culturas distintas representa una gran riqueza cuando se vive el intercambio como fuente de recíproca prosperidad. Esto se llega a convertir en un serio problema cuando se considera la pluralidad de 
culturas como una amenaza en contra de la cohesión social, de la custodia y del ejercicio de los derechos individuales o comunitarios. La consecución de una relación equilibrada y pacífica entre culturas preexistentes y culturas nuevas, caracterizadas a menudo por usos y costumbres que se presentan contrastantes, no transita por un camino ajeno a las dificultades y obstáculos.

La laicidad protege a las creencias cuando se deja de lado la idea de que la verdad se descubre en el mundo de las cosas o que viene directamente revelada por parte de tal o cual Dios. La verdad no se encuentra, sino que se construye, porque es histórica, es fruto de la racionalidad lingüística y el consenso. No se aboga por sincretismos conciliadores, sino por una construcción de la verdad que se logra en el consenso racional (Ribeiro, 2015, p. 34-39). La verdad está en las proposiciones, se construye desde la suposición y pasa por el diálogo y la pertinencia del léxico.

Esta perspectiva de protección a la religión significa, entonces que la "laicidad" es la actitud de quien respeta las verdades que brotan del conocimiento natural sobre el ser humano que vive en comunidad, aun cuando tales verdades sean enseñadas al mismo tiempo por una religión específica. La laicidad protege a la religión porque capacita a las personas para apartarse de cualquier texto religioso que proponga una moral no aceptable, sea total o parcialmente. Una persona con esta herramienta, desde luego que podrá, como derecho, participar en algún tipo de concepción y organización religiosa, pero con la conciencia de que la moral de esa religión es una construcción histórica, i.e., la moral no es creación de los dioses, la moral no está fundamentada por la religión, sino, más bien, la religión es expresión simbólica de la moral. El asesinato, por ejemplo, está prohibido humana y racionalmente, pero, además, desde el mito, los diferentes dioses manifiestan su rechazo frente a esta acción, lo que lleva a la conclusión de que lo bueno y benéfico para los seres humanos no brota de la voluntad divina, sino que lo bueno y benéfico para los hombres, es aceptado también por la divinidad. Lo contrario significaría que la divinidad es voluntariosa y arbitraria. 
Desde lo anteriormente expuesto, se puede establecer que habrá que tener mucho cuidado de no caer ni en el paternalismo moral ni en el fundamentalismo religioso, porque convierten la religión en ideología; pero también habrá que tener igualmente sumo cuidado para no caer, tampoco, ni en el exclusivismo científico ni en el pragmatismo tecnológico, porque convierten a la tecnociencia en ideología.

En el diálogo llamado Eutifrón (Platón, 1903) queda puesto de manifiesto que la ética no se fundamenta en la religión, sino al contrario. Lo que es aceptado como moralmente bueno, tiene características de obligatoriedad para cualquier tipo de divinidad. Dios mismo tendría también que ser moralmente bueno. Identificar la moral religiosa con la bioética puede, de hecho, sofocar la libertad religiosa e incluso limitar o negar otros derechos humanos inalienables.

9e Eut. - En cuanto a mí, afirmaría que es pío lo que agrada a todos los dioses y que, por el contrario, lo que todos los dioses odian es impío. Sóc. - ¿No es cierto que debemos examinar, Eutifrón, si, a su vez, esto está bien dicho, o bien debemos dejarlo? De este modo aceptamos, tanto en nosotros como en los otros, el que, si simplemente uno dice que algo es así, admitimos que es así. ¿Acaso debemos examinar qué dice el que así habla?

Eut. - Debemos examinarlo; sin embargo, yo creo que lo que hemos dicho ahora está bien.

10a Sóc. - Pronto, amigo, lo vamos a saber mejor. Reflexiona lo siguiente: ¿Acaso lo pío es querido por los dioses porque es pío, o es pío porque es querido por los dioses? Eut. - No sé qué quieres decir, Sócrates.

10d Sóc. - ¿Qué decimos, pues, sobre lo pío, Eutifrón? ¿No es amado por todos los dioses, según tus palabras? Eut. - Sí. Sóc. - ¿Acaso, porque es pío, o por otra causa? 
Eut. - No, por ésta. Sóc. — ¿Luego porque es pío se lo ama, pero no porque se lo ama es, por eso, pío? Eut. —Así parece. Sóc. - ¿Pero, porque lo aman los dioses, es amado y agradable a los dioses? Eut. - ¿Cómo no? Sóc. — Por tanto, lo agradable a los dioses no es lo pío, Eutifrón, ni tampoco lo pío es agradable a los dioses, como tú dices, sino que son cosas diferentes la una de la otra.

10e Eut. - ¿Cómo es eso, Sócrates? Sóc. —Porque hemos acordado que lo pío es amado porque es pío, pero no que es pío porque es amado. ¿No es así? Eut. — Sí. (Perseus Digital Library, http://www.perseus.tufts.edu/hopper) ${ }^{7}$

\section{Autonomía como expresión de la capacidad de elección}

Las leyes éticas, tal como se ha puesto de manifiesto, no son producto de la voluntariedad ni de la arbitrariedad de los dioses, sino que consisten en normas establecidas históricamente por los diversos grupos de seres humanos. La ética es una construcción histórica y plural, a la que los mismos dioses tendrían que sujetarse. No se podría aceptar como moralmente buena una divinidad que establezca leyes que consistan en caprichos arbitrarios, tales como matar a los enemigos o apropiarse de sus tierras o demás bienes materiales.

La laicidad posibilita que la bioética delibere sobre los diversos problemas que se le presentan con apertura de criterio. Los seres humanos, en la actualidad, se enfrentan a una

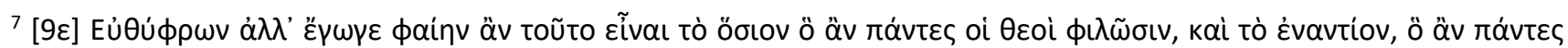

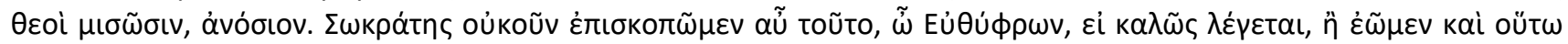

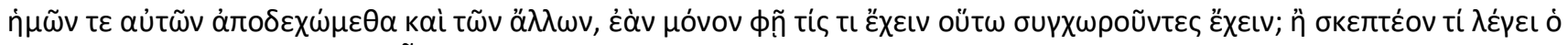

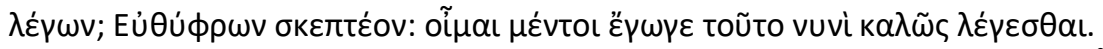

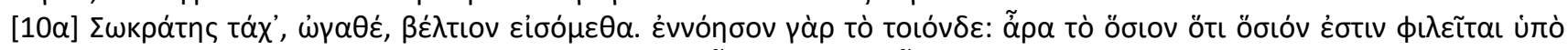

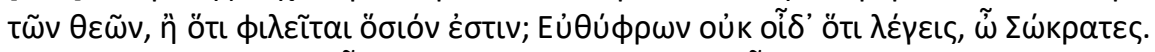

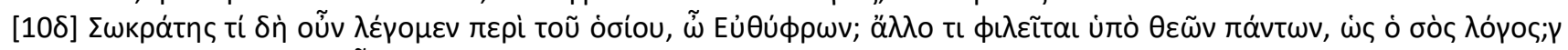

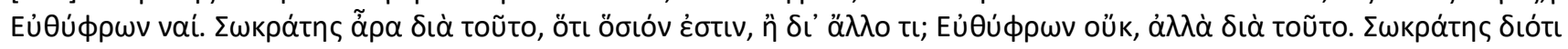

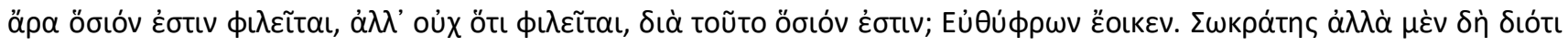

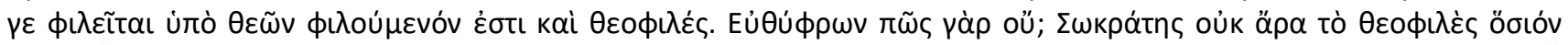

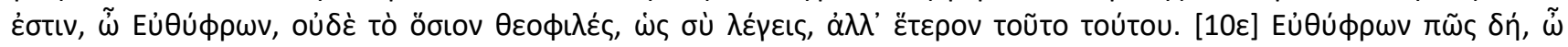

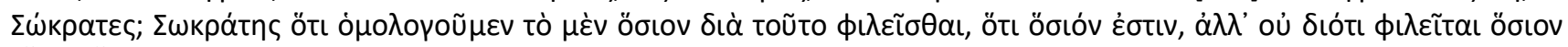

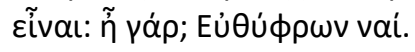


transformación en el modo de concebir la moralidad. Es innegable que Kant inventó el concepto de moralidad como autonomía (Schneewind, 2009, p. 23), pues se convierte en ese parteaguas en las concepciones de la moralidad basadas en la obediencia y que dan origen a las concepciones morales basadas en la autolegislación y el autogobierno, i.e., en la autonomía. En la actualidad, se ha pasado de una moralidad en la que lo más importante era la obediencia a Dios, quien instruía, ordenaba y castigaba a través de la revelación y del clero, a una moralidad de autonomía, lo cual significa que:

Concebir la moralidad como autogobierno ofrece un marco contextual para un espacio social en el que cada uno de nosotros puede pretender controlar debidamente nuestras propias acciones sin interferencia del Estado, la Iglesia, los vecinos o aquellos que pretenden ser mejores o más sabios. La moralidad, que antiguamente se entendía como obediencia, no tenía estas implicaciones. La filosofía moral de principios de los tiempos modernos en la que nació la concepción de la moralidad como autogobierno aportó de este modo una vital contribución a la ascensión en Occidente de la visión liberal sobre la forma correcta en que individuo y sociedad se relacionan. Tal modo de vida no se habría desarrollado sin la labor de los filósofos morales (Schneewind, 2009, p. 23).

Desde esta perspectiva, se puede descubrir la autonomía como la gran puerta que hay que abrir y cruzar con valentía y prudencia, i.e., con sabiduría práctica, con frónesis, ${ }^{8}$ ya sea en el ámbito de la deliberación moral en investigación con seres humanos, investigación social, o en las áreas de la ética medioambiental, de la ética de la biotecnología o los comités de ética. La decisión ha de estar en manos del agente moral, que es autónomo y es el protagonista de las deliberaciones morales. Es un ser en interrelación e interdependencia, responsable y competente, orientado

\footnotetext{
${ }^{8}$ Del griego: Фрóvnoıs, phronēsis
} 
por la sabiduría práctica e invitado a seguir la metodología de la casuística contemporánea, toda vez "que la moralidad es un hecho histórico y, por tanto, históricamente contingente. Cada sociedad tiene su propia moralidad" (Hall, 2013, p. 95). Quien ha de decidir es cada hombre y cada mujer sobre la base de la prudencia o sabiduría práctica. El ser humano autónomo, responsable, que se conoce y cuida de sí, tiene el derecho de decidir. Por eso, las siguientes palabras del Estagirita son totalmente apropiadas para lo que se ha expresado hasta aquí:

Está claro, pues, por lo que hemos dicho, que no es posible ser bueno en sentido estricto sin prudencia, ni prudente sin virtud moral. Esta circunstancia refutaría el argumento dialéctico según el cual las virtudes son separables unas de otras, pues la misma persona puede no estar dotada por naturaleza de todas las virtudes, y así puede haber adquirido ya algunas, pero otras todavía no. Esto, con respecto de las virtudes naturales, es posible, pero no en relación con aquellas por las que un hombre es llamado bueno en sentido absoluto, pues cuando existe la prudencia, todas las otras virtudes están presentes. Y es claro que, aun cuando no fuera práctica, sería necesaria, porque es la virtud de esta parte del alma, y porque no puede haber recta intención sin prudencia ni virtud, ya que la una determina el fin y la otra hace realizar las acciones que conducen al fin (Aristóteles, 1998, pp. 289-290) ${ }^{9}$.

\section{Aceptación de la religión y ámbito de su intervención}

La religión no se excluye para la resolución de problemas (Jobin, 2006, pp. 5-7), sólo que se hace necesario establecer ciertos límites prudenciales a su intervención, porque muchas veces,

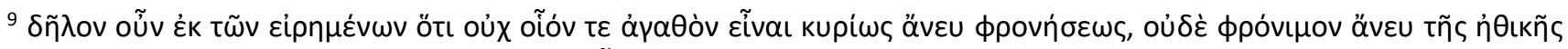

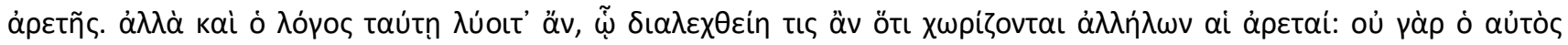

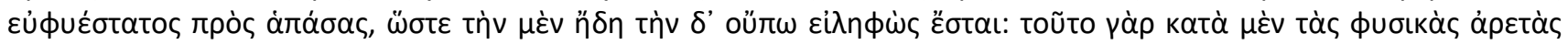

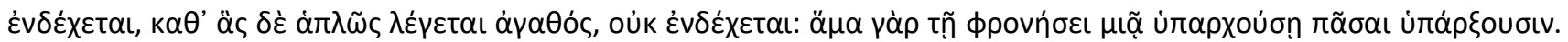

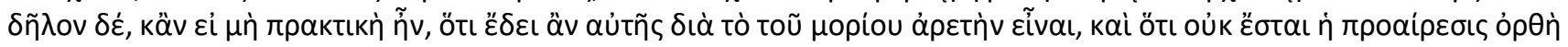

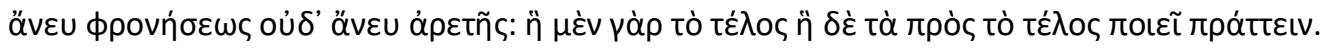


cuando se tiene que dar una respuesta a algún dilema dentro de los debates bioéticos, las religiones miran con perplejidad la profunda y compleja exigencia que presentan aquellos problemas que afectan a preocupaciones que pueden denominarse comunes a la bioética y a la religión, i.e., el inicio y el final de la vida, la salud, la reproducción, la clonación, el trasplante de órganos, etcétera, pero que, si se mira con honestidad y sinceridad, son preocupaciones que van más allá de la capacidad de cualquier tipo de fe para encararlos. Los dilemas que presentan la ciencia y la tecnología suponen retos que desbordan los contenidos del credo, de la liturgia y de los códigos de conducta moral de cualquier religión. Lo que se genera en estas situaciones, entonces, son episodios de obstrucción, malentendidos, descalificaciones y luchas estériles, en donde las personas, que están en el centro de la ciencia, la tecnología y la religión, terminan con graves heridas, ya sea por exceso o por defecto en el modo como se busca que sean protegidas. Hoy día se puede observar que las diferentes religiones dan muestras de preocupación por la bioética y sus dilemas, y deciden posar su mirada sobre ella; sin embargo, no se puede pasar por alto que los intereses propios de los distintos tipos de organización confesional contaminan esa preocupación, pues el rigor metodológico necesario para abordar la bioética desaparece detrás de ellos. Al respecto, Salazar (2006) afirma:

La batalla no debe ser contra la fe, sino contra los intentos de algunos creyentes (y de sus iglesias) por imponerse, por excluir las 'otras creencias' y las 'no creencias' del espacio público. El laicismo así entendido no es patrimonio exclusivo de una ideología, de una cultura o de los agnósticos o los ateos, sino que constituye el terreno común, la condición de posibilidad, de todas las culturas, ideologías o credos que sean compatibles con los principios de la democracia constitucional. Constituye, además, el punto de partida de algunas políticas democráticas concretas. Por ejemplo, se me ocurren las siguientes: a) ninguna iglesia o religión debe recibir beneficios o privilegios económicos por parte del estado; b) las normas e instituciones políticas y 
jurídicas únicamente deben responder a los principios del estado democrático de derecho; c) ninguna identidad cultural debe estar por encima de los derechos de libertad individuales dentro de los cuales destacan las libertades de pensamiento y religiosa; d) ningún gobierno debe orientar sus decisiones y acciones inspirándose en principios religiosos; e) la ciencia y el desarrollo tecnológico deben responder a la razón científica y a la ética de la responsabilidad de sus promotores y ejecutores y no a los dogmas de fe de los poderosos y; así sucesivamente (2006, p. 46).

Cuando emergen a la luz algunas declaraciones provenientes de comunidades religiosas, la duda acuciante es sobre su preocupación fundamental, i.e., si se preocupan por defender al ser humano o si su máximo interés es salvaguardar su particular ortodoxia, en otras palabras, a veces no queda claro si su interés principal tiene como núcleo fundamental a cada persona y sus circunstancias o si lo que buscan preservar es el dogma y la, así llamada, ortodoxia (Arregui, 2013, Blog personal) ${ }^{10}$. Esta duda trae como consecuencia que se dé una postura defensiva ante este tipo de declaraciones, porque, como se ha visto, no es conveniente tratar como cuestión religiosa lo que es cuestión científica y ética. Por ejemplo, no se pueden descartar las técnicas de fecundación in vitro diciendo que "los valores específicamente humanos de la sexualidad exigen que la procreación de una persona humana sea querida como el fruto del acto conyugal específico del amor entre los esposos" (Congregación para la Doctrina de la Fe, 2008, p. 5). Tampoco se deberían llamar "hermanos... seleccionados para la muerte" a los preembriones

\footnotetext{
10 "Cuando en una religión predominan la imposición y el miedo, hiere la vida. Cuando blande la condena, hiere la vida. Y hay que lamentar que la Iglesia católica que se dice "de Jesús", llamada a curar y cuidar, eche mano tan a menudo de interminables y ásperas condenas cuando habla de la vida en su azaroso origen y en su incierto final: los anticonceptivos, la reproducción médicamente asistida, la investigación con embriones en estadio preimplantatorio, la píldora del día después para impedir la fecundación, toda interrupción del embarazo en todas las fases y en todos los casos, las medidas que abrevian la vida cuando ésta ha dejado de ser para alguien lo suficientemente digna... todas estas prácticas y quienes las realizan están condenadas. Pero las condenas no son amigas de la vida. Las condenas son rígidas y agrias.
} 
que no se han implantado en el proceso de un diagnóstico pre-implantatorio. No es éticamente correcto usar la terminología demagógica de "selección eugenésica" o "bebé-medicamento" para referirse a la aplicación de los procedimientos de diagnóstico pre-implantatorio y selección embrionaria, sin distinguir si se llevan a cabo responsable o irresponsable (Secretaría General de la Conferencia Episcopal Española, 2008, p. 2).

\section{La laicidad en la bioética protege la religión}

A partir de lo que se ha expuesto hasta este momento, se puede ver que la bioética que deja de lado a la religión es una bioética sin adjetivos, pero cuya búsqueda está orientada a encontrar aquello que sirve para crear lazos de unidad entre todos los seres humanos, desde la base del conocimiento científico, con tolerancia y sin dogmatismos. Ésta es la búsqueda incesante de una plataforma ética que respete las diferencias inherentes a las variadas comunidades de seres humanos, en el entendido de que la moralidad es una construcción histórica. Lo que se pretende en la organización civil, ahora sí, con el adjetivo "laica", es la consecución del bien común. Desde esta óptica, una bioética separada de la religión es garantía de protección para las distintas perspectivas religiosas. Si la bioética se decantase por una perspectiva religiosa, no habría espacio ni para la tolerancia ni para el pluralismo ni para la autonomía. Cuando se recibe una verdad revelada, sólo hay espacio para la heteronomía y para la exégesis.

En la deliberación moral sobre la homosexualidad, una sociedad laica no tendría por qué definir si la homosexualidad es buena o mala, normal o anormal, natural o antinatural. Lo que sí tendría que hacer es, sencillamente constatar que existen personas homosexuales irreversibles, (en quienes no parece cumplirse exactamente aquello de "varón y hembra los creó", que es una afirmación confesional) a las cuales no se les debería negar una serie de posibilidades sociales, como tener una pareja, heredar, poseer en común, reconocidas a todos.

Desde el estatus último de la ciencia, la bioética protege las diversas perspectivas religiosas, tanto las que están a favor de permitir que las personas homosexuales sean 
consideradas con los mismos derechos y obligaciones de los demás seres humanos, como de las que las consideran como comportamientos contrarios a la verdad revelada. Una bioética confesional, se vería en la necesidad de proclamar que "la Tradición ha declarado siempre que:

los actos homosexuales son, por su intrínseca naturaleza, desordenados y que no pueden recibir aprobación en ningún caso. Son contrarios a la ley natural, cierran el acto sexual al don de la vida, no proceden de una verdadera complementariedad afectiva y sexual, no pueden recibir aprobación en ningún caso (Catecismo de la Iglesia Católica, núm. 2357, 2012).

La bioética, en cambio, al alejarse de la religión, protege las distintas perspectivas religiosas, lo cual sería imposible desde una postura religiosa. De ahí que Paulette Dieterlen, exconsejera de la Comisión Nacional de Bioética, cuando se le preguntó sobre los retos más importantes para la bioética hoy en día, haya respondido:

Creo que uno de los grandes retos que tiene actualmente la bioética es lograr que todos entendamos que debe ser una disciplina laica, que tienen que ir avanzando con argumentos que vayan de acuerdo con lo que rige nuestro país, que es la laicidad. Porque todavía es muy fácil que se metan creencias religiosas, de cualquier religión, pero es muy importante conservar la laicidad (Nava, 2017, p. 1).

\section{Conclusión}

La laicidad es un mínimo que posibilita el máximo del ideal de felicidad. La laicidad no postula ideales de felicidad, porque eso le compete a la moral. La función de la bioética no es hacer que las personas sean felices. Desde luego que tal función le pertenece mucho menos a una constitución o a algún gobierno. La bioética, en cambio, tiene una función, la de definir un escenario en el que las personas puedan ser felices (Blackburn, 2002, p. 150). Uno de esos 
escenarios es, precisamente, la laicidad, en donde, sobre la base del estatus último de las ciencias, incluidas las que se dedican a estudiar las religiones, se promueve, se ofrece y se exige el respeto: el mandamiento de respeto "respétense unos a otros", es más plausible que el mandamiento del amor. La religión, entonces, puede y debe acercarse a la bioética, pero sin arrogarse el derecho de intromisión para imponer normas de moralidad a la sociedad civil, que es heterogénea y plural. La bioética, por su parte, podría ser invitada al movimiento de diálogo interreligioso, con la finalidad de ayudarlo a transformar, partiendo de los nuevos datos aportados por la ciencia, sus paradigmas y conclusiones, pero sin imponer interpretaciones de sentido sobre la vida, la muerte, el dolor, la salud y la enfermedad (Masiá, 2012, pp. 51-52).

\section{Referencias}

Arellano, S. (2013). Teoría ética para una ética aplicada. Querétaro: UAQ.

Aristóteles. (1998). Ética Nicomáquea. Madrid: Gredos. Traducción: Julio Pallí Bonet.

Arregui, J. (2013). Cuidar la vida. Recuperado de, http://blogs.periodistadigital.com/josearregi.php/2013/01/31/cuidar-la-vida

Blackburn, S. (2002). Sobre la bondad. Una breve introducción a la ética. España: Paidós.

Bovero, M. (2013). Laicidad. Un concepto para la teoría moral, jurídica y política. En Salazar Ugarte, Pedro y Capdeville, Pauline, Coord., Para entender y pensar la laicidad. México: UNAM, Porrúa.

Carta Apostólica Octogésima Adveniens, n. 50, Obtenido de: http://w2.vatican.va/content/paulvi/es/apost letters/documents/hf p-vi apl 19710514 octogesima-adveniens.htm|\#fnref36 Carta Apostólica Octogésima Adveniens de Su Santidad el Papa Pablo VI, Vaticano, 14 de mayo de 1971. Recuperado de http://w2.vatican.va/content/paulvi/es/apost letters/documents/hf p-vi apl 19710514 octogesima-adveniens.html Catecismo de la Iglesia Católica. Recuperado de http://www.vatican.va/archive/catechism sp/index sp.html 
Comité Ejecutivo de la Conferencia Episcopal Española, (CEE, 2006). Ante la licencia legal para clonar seres humanos y la negación de protección a la vida humana incipiente (Conferencia Episcopal Española [CEE], 2006).

Congregación para la Doctrina de la Fe, (2008). Instrucción Dignitas Personae, sobre algunas cuestiones de bioética.

Cortina, A. (2009). Las fronteras de la persona. El valor de los animales, la dignidad de los humanos. Madrid: Taurus.

González, J. (2008). "Introducción", en Perspectivas de bioética, Fondo de Cultura Económica, México.

Gracia, D. (2002). De la bioética clínica a la bioética global: treinta años de evolución, en Acta bioethica, 8 (1), pp. 27-39.

Guy J. ((19 de octubre, 2017)). "Les discours religieux dans l'espace public de la bioéthique ", en Éthique publique. Disponible en línea: http://ethiquepublique.revues.org/1875

Hall, R. (2013). Justificación de una metodología de la ética aplicada: una glosa sobre la casuística. En Hall, R. y Arellano J. S. La casuística. Una metodología para la ética aplicada. México: Fontamara.

Hall, R. (2012). Las fronteras de la persona: El valor de los animales, la dignidad de los humanos. Diánoia, 57(68), 203-213.

Hottois, G. ((19 de octubre, 2017)). "Les enjeux philosophiques laïques de la bioéthique", en Revue internationale d'éducation de Sèvres, Disponible en línea: http://ries.revues.org/4151Gilbert Hottois. La vida en Cristo, en Catecismo de la Iglesia Católica. Recuperado de:

http://www.vatican.va/archive/catechism sp/p3s2c2a6 sp.html

León, A. P.; Risco del Valle, E. y Alarcón, C. (2014). Estrategias de aprendizaje en la educación superior en un modelo curricular por competencias. Recuperado de http://www.scielo.org.mx/scielo.php?script=sci arttext\&pid=S0185-

\section{4\&lng=es\&t|ng=es}

Lolas, Fernando, \& Rodriguez, Eduardo. (2012). Ethics in psychosocial and biomedical research: A training experience at the Interdisciplinary Center for Bioethics (CIEB) of the University of Chile. Acta bioethica, 18(1), 9-56.

Masiá, J. (2012). "Deliberación bioética y perspectiva religiosa", en Revista Iberoamericana de Teología, Núm. 14, enero-junio, 2012, p. 51-52. 
Nava, A. (2017). Mantenerse separada de la religión, el mayor desafío de la bioética. Recuperado de http://www.conacytprensa.mx/index.php/ciencia/salud/16512-bioetica-justicia-distributivapaulette-dieterlen

Plato. (1903). Platonis Opera, Euthphr., ed. John Burnet. Oxford University Press. Plato. Recuperado de: http://perseus.uchicago.edu/perseus-

cgi/citequery3.pl?dbname=GreekFeb2011\&getid=0\&query=Pl.\%20Euthphr.\%209d

Platón. (2018). Diálogos I. Madrid: Gredos. Traducción de Calonge Ruiz, Julio.

Ribeiro, G. (2015). Verdad y argumentación jurídica. México: Porrúa.

Rodríguez, E. (2010). Religión y Bioética. Acta bioethica, 16(1), 7-8. Disponible en línea: https://dx.doi.org/10.4067/S1726-569X2010000100001.

Rosas-Jiménez, C. A. (2011). La solidaridad como un valor bioético. Persona y Bioética, 15 (1).

Salazar, P. (2006). "Laicidad y democracia constitucional", en Isonomía: Revista de Teoría y Filosofía del Derecho. México: Instituto Tecnológico Autónomo de México, [s.a.], núm. 24 (Abril), Disponible en línea: http://www.cervantesvirtual.com/obra/laicidad-y-democracia-constitucional-0

Schneewind, J. B. (2009). La invención de la autonomía. Una historia de la filosofía moral moderna, Fondo de Cultura Económica, México.

Secretaría General de la Conferencia Episcopal Española, (CEE, 2008). Curar a los enfermos, pero sin eliminar a nadie. Aclaraciones sobre los hechos implicados en el nacimiento del llamado primer "Bebé medicamento" (Conferencia Episcopal Española [CEE], 2008). 